\title{
On the use of nano fibrillated kenaf cellulose fiber as reinforcement in polylactic acid biocomposites
}

\author{
Q Ahsan ${ }^{1,2}$, T.S.S. Carron ${ }^{2}$, and Z. Mustafa ${ }^{2}$ \\ ${ }^{1}$ Carbon Research Technology Group, \\ Faculty of Manufacturing Engineering, Universiti Teknikal Malaysia (UTeM) \\ ${ }^{2}$ Faculty of Manufacturing Engineering, Universiti Teknikal Malaysia (UTeM) \\ 76100 Durian Tunggal, Melaka, Malaysia \\ Phone: +60102630180; Fax: +6063316431 \\ *Email: qumrul@utem.edu.my
}

\begin{abstract}
In this study, nano fibrillated kenaf cellulose (NFKC) derived from kenaf fiber after varying chemico-mechanical treatments were introduced into poly lactic acid (PLA) as reinforcements to improve the mechanical and morphological properties of the biocomposites. The new strategy was aiming to realize the synergistic effects of chemical treatment and mechanical fibrillation process parameters (blending speed and time) for yielding nanofibers and its reinforcement effects on the properties of biocomposites. The yield percentage of the NFKC was determined using centrifugal method and the NFKC fibers with PLA pellet were hot pressed to form NFKC-PLA composites. The distribution and dispersion morphologies of NFKC in NFKC-PLA composites were observed by using optical microscope (OM) and scanning electron microscope (SEM). The reinforcing effect on the mechanical properties of NFKC-PLA composite was investigated by tensile strength test. Average length and diameter of fibrillated fibers were decreased with the concurrent increase of blending speed and time. The maximum increase in tensile strength of $59.32 \%$ and elongation of $100 \%$ were observed for NFKC-PLA composite with NFKC yielded at a blending speed and time of $15000 \mathrm{rpm}$ and 15 minutes as compared to pure PLA. The tensile properties indicated that the strength and modulus were improved with increased nanofiber contents.
\end{abstract}

Keywords: Nano fibrillated kenaf cellulose; poly lactic acid; biocomposite; morphology; tensile properties.

\section{INTRODUCTION}

Poly lactic acid (PLA) already well-known as linear aliphatic polyester is prepared from the activity of microorganisms [1,2] and can be one of the most promising biodegradable polymers, which have biocompatibility and good mechanical properties. It has tensile strength of 48 to $53 \mathrm{MPa}$ and modulus of $3500 \mathrm{MPa}$ [3]. However, the insufficient impact strength, inherent brittleness and low thermal stability of PLA are limiting the scope of its application. Strategies include copolymerization, polymer blends and addition of plasticizers, 
nanoscale reinforcing fillers and natural fibers to improve mechanical properties for commercial use [4-7]. PLA polymers are also hydrophilic in nature therefore absorb moisture helping in its pathway of bio-degradation. Biodegradable polymers are other alternatives for petroleum derived polymers since they are overall biodegradable and renewable without releasing any toxic compounds to the environment [8].

When compared to conventional fibers, natural fibers have the advantages of biodegradability, light weight and low environmental impact. Besides, when blends with polymer, it provides good mechanical properties to the polymer matrix composites. Nanocellulose as the name implies derived from any cellulolosic source, viz wood and plant fibers is composed of nano-sized cellulose fibrils with a high aspect ratio (length to width ratio). Typical diameters and lengths are in the range of 5-20 nm and $10 \mathrm{~nm}-10 \mu \mathrm{m}$ respectively [9]. In particular, cellulose nano fibrils (NFC) are ideal reinforcing materials for nanocomposites as they have high mechanical strength performance, high aspect ratio and large specific surface area. Especially the stiffness of crystalline nano cellulose has been shown to be in the order of 140-220 GPa, which is comparable to synthetic fibers that are currently used as reinforcement for plastics [10]. When NFC is aligned, it can be a good reinforcement to its composites. Even though the nanofibers are randomly oriented, it might be possible to enhance the composites' properties [10]. The NFC in the bio nanocomposite materials also gives enhancement in thermal stability because of a strong NFC bond that is formed within the matrix [11].

The separation of nano cellulosic materials from plant sources gives a big challenge as it requires high energy. Other than that, the cellulose tends to absorb moisture which increases the challenge of fibrillation process. High quality of NFCs can be obtained at low cost through mechanical disintegration of wood pulp fiber after enzymatic or chemical pretreatments. The biggest challenge in fibrillation process of cellulose is to minimise the damage of fibers therefore, it is essential to comprehend the mechanism by which pulp fibers either are partially or fully fibrillated and become completely uniformed NFC. The successful mechanical extraction of nanofibers from wood was reported by Istva and David [12] using wood pulp in a high pressure homogenizer. The homogenisation process resulted in disintegration of the wood pulp into sub-structural microfibrils with strongly entangled and disordered networks of cellulose nanofiber [13]. Another effective chemico-mechanical treatment reported by Habbibi [14] is to produce nanofiber of $5 \mathrm{~nm}$ in width from pear peel pulp with disintegration in a blender followed by homogenization by 15 passes through a laboratory homogenizer, operated at 500 bars and $90-95{ }^{\circ} \mathrm{C}$. Blenders have also been employed to obtain chitin nanofibers from crab shell [15]. CNF or partial isolation of microfibrils are also derived from chemically treated banana rachis [16].

The materials properties of virgin polymer will show significant improvement when nanofibers are well incorporated in polymer matrices. Extensive studies on different processing methods and the preparation of nanocomposites using nanocelluloses as reinforcement in PLA are being reported [17-19]. Dispersion plays a vital role in improving the strength of biodegradable nanocomposites, as nanoscale particles that are separated homogenously will give better interfacial contact between the matrix and the particles. It is hard to quantify the dispersion of NFCs as the nanofibers greatly blurred the crystalline texture. Hence, the mixing process is important to ensure full utilization of the reinforcing properties of the NFC. In order to facilitate the dispersion of nano cellulose in PLA matrix, surfactant or carrier (PVA) compounded with nanocellulose were successfully processed by 
extrusion to prepare PLA nanocomposite $[19,20]$. PLA, a biopolymer, is a non-polar and hydrophobic, which complicates the use of NFC as reinforcement since it has hydrophilic properties. Generally, to improve the dispersion of reinforcements, aqueous polymer particles are mixed with latex matrix. This method enables direct wet mixing of the polymer particles and matrix in their dispersed state, thus preventing aggregation on drying. Okubo and co-workers [21] simply used water as carrier where the PLA water slurry was premixed with fibrillated cellulose and processed using a roller mixer followed by drying and injection molding and reported that the well-dispersed fibrils with lower concentration improved the composites' modulus by $31 \%$ and the fracture energy by almost $200 \%$. In an another study [10], nanofibers separated from kenaf pulp were mixed with PLA matrix in a solvent mixture followed by extrusion process and injection molding. The morphology studies of PLA and its nanocomposites showed that a relatively good dispersion was achieved as no CNF aggregates were visible in the fracture surfaces. In addition the modulus of the resultant PLA matrix composite was increased from $2.9 \mathrm{GPa}$ to $3.6 \mathrm{GPa}$ with the addition of $5 \mathrm{wt} . \%$ nanofibers, and a $21 \%$ increase of tensile strength.

In the current study, combination of chemical and mechanical treatment were applied for the yielding of micro and nanofiber respectively from raw kenaf fiber. Initially, kenaf fibers were washed with soap to remove dirt, grease/oil or other small particles. Later, HCL tratment ensured removal of lignin and pectin from kenaf fiber followed by $\mathrm{NaOH}$ treatment removed the hemicellulose contents and made the fiber into pulp which may enrich by plant cell wall cellulose. Subsequntly, pulps were placed in a high speed blender to obtain a higher yield of nanofiber cellulosic from the kenaf pulps by varying blending speed and time. Finally vacuum filtered is used to collect the enriched NFKC. The effect of yielded nanofiber as reinforcing phase for PLA matrix on the mechanical properties of NFC- PLA composite was evaluated through tensile testing. Microscopic analysis was used to study of nanofibers morphology and fracture surface of nanocomposites.It is found that blending time and speed have substantial effect on yielding of nanofibers which improves the tensile properties of composites.

\section{METHODS AND MATERIALS}

\section{Kenaf Fiber and Fibrillation}

In this research, kenaf fibers were collected from local supplier and these were soaked in 500 $\mathrm{ml}$ of $3.7 \mathrm{wt} . \%$ hydrochloric acid solution (HCL) at $70^{\circ} \mathrm{C}$ for 2 hours to solubilize the hemicellulose. Afterwards hydrolysed fibers were immersed into $500 \mathrm{ml}$ of $2 \mathrm{wt} . \% \mathrm{NaOH}$ solution for 2 hours at $70^{\circ} \mathrm{C}$. This process is to disrupt the lignin structure and breakdown of pectin. A suspension of pulp fibers was agitated using a blender (Vita Mix 5200). We fibrillated 1 litre of the suspension with fiber content of 0.7 wt $\%$ and blending speeds of 7500, 15 000, and $23000 \mathrm{rpm}$ (maximum speed). The blending time was set to 5, 10 and 30 minutes. The treated pulp was hydrolyzed by $3.7 \mathrm{wt} \% \mathrm{HCl}$ and dispersed in water at a fiber content of $0.2 \mathrm{wt} \%$, and each mixture was stirred by a magnetic stirrer for $1 \mathrm{~h}$. Slurries were vacuum-filtered using a polytetrafluoroethylene membrane filter $(0.1 \mu \mathrm{m}$ mesh $)$. 


\section{Poly Lactic Acid (PA)}

Poly Lactic Acid (PLA) Type 6 Series was collected from Nature Works Ingeo ${ }^{\text {TM }}$. The PLA has a density of $1.25 \mathrm{~g} / \mathrm{cm}^{3}$ and melting point range from $130^{\circ} \mathrm{C}$ to $170^{\circ} \mathrm{C}$ with amorphous to crystalline grades.

\section{Chemicals}

Hydrochloric acid and sodium chloride were purchased from Poly Scientific Enterprise Sdn. Bhd. (Melaka) and were used in chemical treatment of kenaf fiber to disrupt the lignin structure and breakdown of pectin.

\section{Nanocomposite Preparation}

Nano composites were prepared using a two-step process: internal mixing and hot compression moulding. In internal mixing procedure, the PLA-to-fillers ratio of the biocomposites was kept at 19/1 according to pre-study. Approximately 50.0 g PLA/FIBERS blends were melt-blended in a Haake Rheomix 600 internal mixer (Gebr. HAAKE GmbH, 123 Germany) at $170^{\circ} \mathrm{C}$ for 10 min with a screw rpm of 50. No processing aids or other additives were used. The nomenclature of treated fibers and the compositions of composites in this study are shown in Table 1.

Table 1. Sample nomenclatures and compositions in this study.

\begin{tabular}{lcccc}
\hline Nomenclature & $\begin{array}{c}\text { PLA } \\
\text { content } \%\end{array}$ & $\begin{array}{c}\text { Blending Speed } \\
(\mathrm{rpm})\end{array}$ & $\begin{array}{c}\text { Blending Time } \\
(\mathrm{min})\end{array}$ & $\begin{array}{c}\text { Fiber Content } \\
5 \%\end{array}$ \\
\hline \multicolumn{1}{c}{ PLA-C } & 100 & 0 & 0 & 0 \\
\hline KF-C-7.5-5 & 95 & 7500 & 5 & 5 \\
KF-C-7.5-10 & & & 10 & 5 \\
KF-C-7.5-15 & & & 15 & 5 \\
\hline KF-C-15-5 & 95 & 15000 & 5 & 5 \\
KF-C-15-10 & & & 10 & 5 \\
KF-C-15-15 & & & 15 & 5 \\
\hline KF-C-23-5 & 95 & 23000 & 5 & 5 \\
KF-C-23-10 & & & 10 & 5 \\
KF-C-23-15 & & & 15 & 5
\end{tabular}

The compounding of biodegradable composites was carried at a ratio of 95\% PLA and 5\% fibers which contain different amounts of NKFC. The weight of the scraped composites was measured according to the volume of the mold. Afterwards, the composites sample undergo preheating process at $180^{\circ} \mathrm{C}$ without any pressure for $1 \mathrm{~min}$ to allow complete melting. The melted composite then pressured for 8 min at 10 tons. Next, it was cold pressed at room temperature. The mold size for tensile test sample was made according to ASTM D638 standard. 


\section{Microscopy Examination}

The diameter and physical changes of the kenaf fibers were observed by optical microscope (OM), model Zeiss Axioskop 2 with magnification of 50. A Zeiss SEM type Evo 50 Series was used to study the morphology of the fibrillated cellulose. To obtain a higher resolution of the fibrillated cellulose which is up to $1 \mathrm{~nm}$, field emission scanning electron microscope of model Carl Zeiss Microscopy Gemini 300 was used. Low accelerating voltage and magnification of range of $12-2,000,000 \mathrm{X}$ was set to get the high resolution image of the fibrillated cellulose. The fracture surfaces resulted from tensile test of composite samples were also placed under the SEM to study the fracture morphology. All samples were coated with gold before SEM observation.

\section{Fourier Transform Infrared Spectroscopy}

FTIR with Attenuated Total Reflection technique (ATR) was used to explore the presence of functional group of the composite. The analysis was carried out by Fourier transform infrared spectroscope that can perform up to 20 scans per second with maximum resolution of 0.5 $\mathrm{cm}-1$. In this project, the functional groups of composite were analyzed within the spectra range from 4000 to $400 \mathrm{~cm}^{-1}$. The FTIR provided information on chemical structures and physical characteristics of the kenaf fibers after undergo chemical treatment. As received kenaf fiber was used as a reference.

\section{Yield in Fibrillated Cellulose}

The yield of fibrillated cellulose was obtained from centrifugation method by a centrifuge machine. In this project, centrifugation of a diluted fibrillate cellulose suspension was to separate the unfibrillated materials from those partially fibrillated. The procedure was carried as follow by using 0.01 grams of dried blended fibers, added into a centrifuge tube that containing $10 \mathrm{ml}$ of distilled water to make a dilute suspension with about 0.1 weightage percent solid content. This suspension was centrifuged at $3800 \mathrm{rpm}$ for 30 minutes to separate the nano fibrillated material from the partially- or non-fibrillated one that settled down as sediments. Then, the sediment fraction was collected by vacuum filtering and was dried in a drying oven. A small amount of the sample from each treatment was oven-dried at $105^{\circ} \mathrm{C}$ for $24 \mathrm{~h}$. The dried specimen was kept in desiccators prior to weighing. The yields after each stage of chemical treatment were calculated as percentage of dried fiber over initial weight of fibrillated cellulose sample.

\section{Tensile Tests}

The tensile tests were performed using a universal testing machine, AG 1 from Shimadzu Corporation, Japan. The crosshead speed was set to $2 \mathrm{~mm} / \mathrm{min}$ with a load cell of $20 \mathrm{kN}$. The tensile tests were performed according to type I tensile specimens (D638-standard test method for tensile properties of plastics) and the gauge length used was $50 \mathrm{~mm}$. The tensile modulus was calculated from the initial part of the slope from stress-strain curves. Five test samples were tested for each material and the average values are calculated. 


\section{RESULTS AND DISCUSSION}

\section{Scanning Electron Microscopy (SEM)}

Chemical treatments are required to avoid any damage during removal of kenaf technical fibers from bast fibers . Figure 1(a-c) exhibits scanning electron micrograph images of as recieved, acid hydrolysis and acid and alkali hydrolysis respectively. Figure 1 (a) shows irregular surface and presence of impurities of as received kenaf fiber but the diameter of the fiber all along the length is uniform. The surface of kenaf fiber after acid treated clearly shows the removal of almost all impurities [Figure 1(b)] but the fiber diameters reduced and varied along its length. Whereas, the surface of the fiber treated with acid followed by alkali treatment as in Figure 1 (c) shows the absence of impurities with the diameter of the fiber reduced to a wider range, due to unequal reaction with alkali. During the high-temperature $\mathrm{NaOH}$ treatment, most of the hemicellulose was hydrolyzed and became water soluble, and the lignin was partially depolymerized. Most impurities around the fibers were removed, which induced the separation of fiber bundles into individual fibers. Figure 2 shows the diameter distribution of as recieved fibers and treated fibers. By referring to Figure 2, the diameter for the as received kenaf fiber was reduced by $70 \%$ from $90.45 \mu \mathrm{m}$ to $26.45 \mu \mathrm{m}$ after the acid and alkaline treatment.

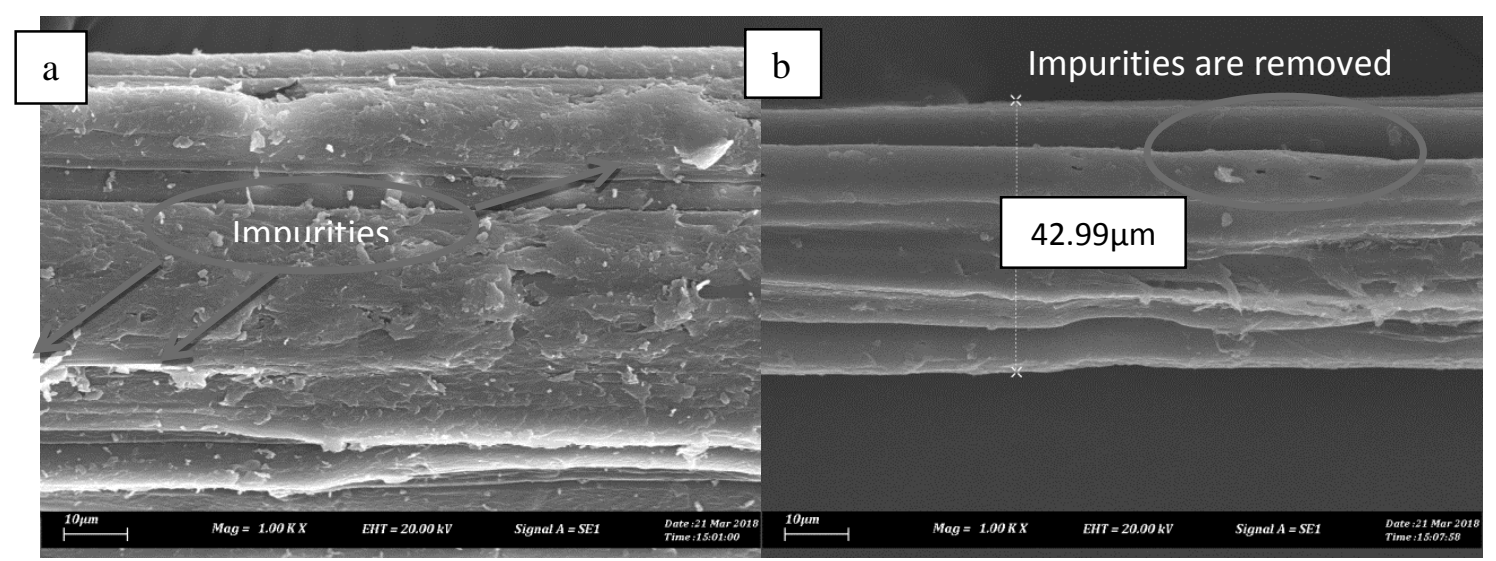




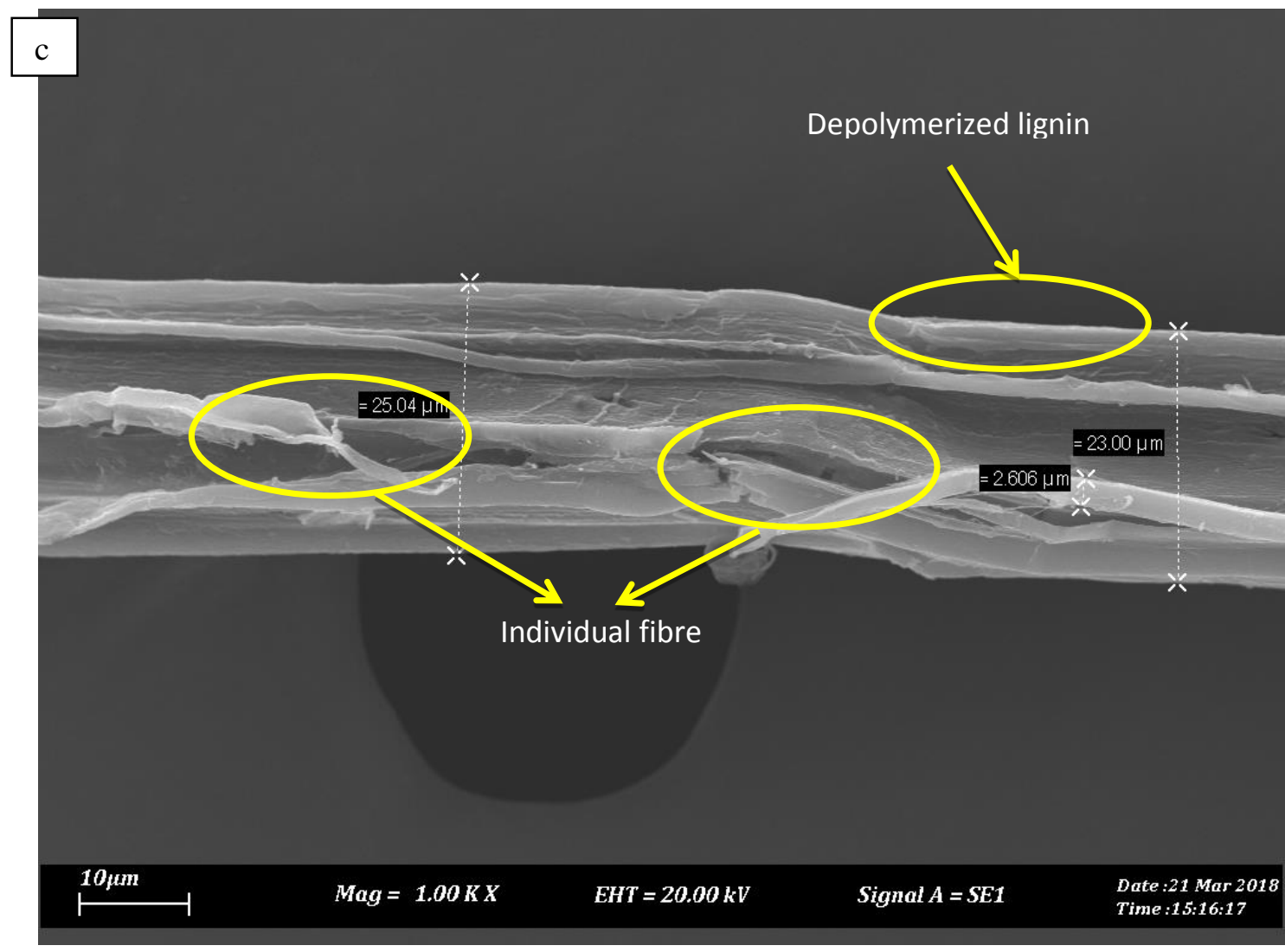

Figure 1. Scanning electron micrographs of the fiber surface topologies of (a) As received kenaf fiber, (b) $3.7 \mathrm{wt} . \%$ of HCL solution treated kenaf fiber and (c) $3.7 \mathrm{wt} . \%$ of HCL solution and 2 wt.\% of $\mathrm{NaOH}$ Treated Kenaf Fiber. 


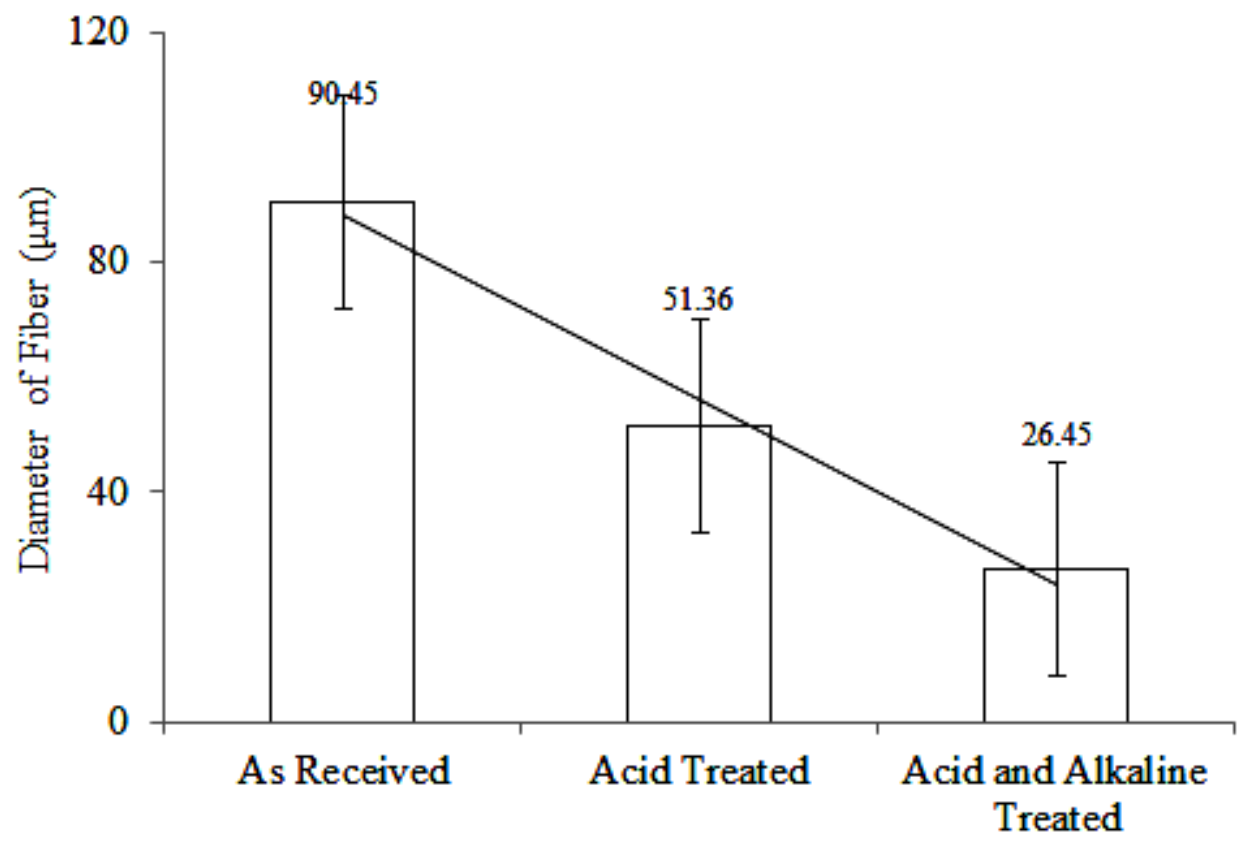

Figure 2. Average diameters of as received and treated kenaf fibers.

\section{Fibrillated Kenaf Fibers Characterization}

\section{Optical Microscopy (OM)}

The Optical Microscopy (OM) was used to determine the average length and diameter of the kenaf fibers after underwent the micro fibrillation process with different blending speed of $7500 \mathrm{rpm}, 15000 \mathrm{rpm}$ and $23000 \mathrm{rpm}$ at different blending time of 5 minutes, 10 minutes and 15 minutes. The OM images of the fibrillated fibers (Figure 3) show the morphological changes of the pulp that is fibers were swollen as the blending speed increased which finally helped the fibers to disintegrate into smaller diameter [Fig. $3 \mathrm{c}$ ] as the blending speed reached to $23000 \mathrm{rpm}$. A similar balloon structure was also observed in the chemical dissolution of pulps [22].

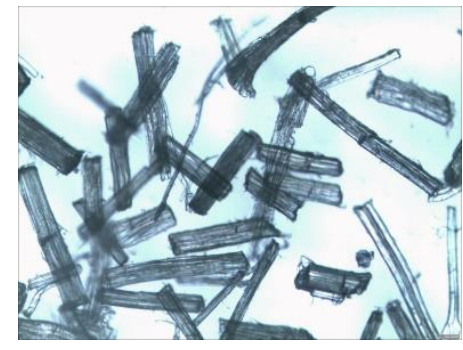

(a)

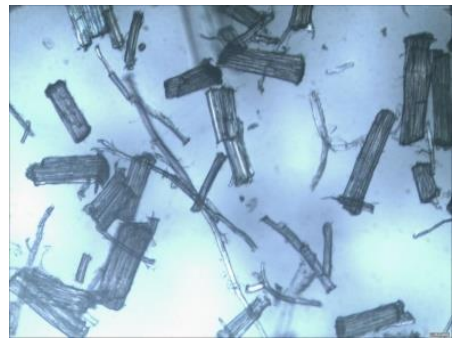

$100 \mu \mathrm{m}$

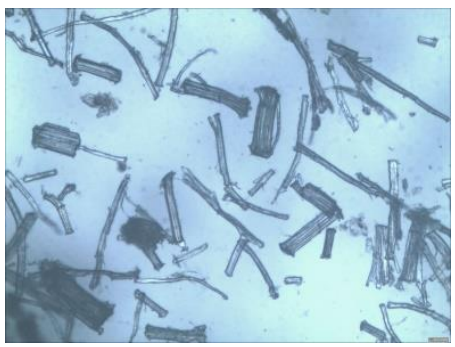

(c)

Figure 3. Optical microscope images of fibrillated kenaf fiber at blending speed and time of (a) $7500 \mathrm{rpm}$ and $15 \mathrm{~min}$ (b) $15000 \mathrm{rpm}$ and $15 \mathrm{~min}$ (c) $23000 \mathrm{rpm}$ and $15 \mathrm{~min}$. 
The effect of fibrillation by varying blending speed and time towards the morphologies of kenaf fibers was investigated by SEM and their micrographs are shown in Figure 4. As the bending time increases, more elementary kenaf fibers are separated from the technical fibers. This may due to the removal of hemicellulose that bonded the cellulose together by chemical pretreatment, therefore the elementary fiber can be isolated. The morphologies of kenaf fiber in three of the micrographs show that even smaller fibrils are coming out from elementary fibers as the blending time increases. This can be clarified by the effective removal of lignin and hemicellulose during the chemical treatment. The skin of the cellulose has started to peel off which is the nanofibrils. The range of elementary fiber diameter is from 10-30 $\mu \mathrm{m}$. It can also be observed that fibrillation developed from the initial surface peeling at sites of weakness present on the cell wall and subsequent splitting of individual fiber wall layers and also reported by other researchers [23, 24] for wood pulp where mechanical blending produces high shear that causes transverse cleavage along the longitudinal axis of the cellulose microfibrillar structure. Different blending speed indicates different fibrillation level occur on the surface of the cellulose fiber. The fibrillated cellulose at the speed of 23000 rpm shows more fibrillation occurs on the surface of the cellulose compared to the other two blending speeds. This indicates a higher blending speed give more fibrillated cellulose. Further presence of nanofibrils was investigated through the Field Emission Scanning Electron Microscopy (FESEM) for the highest blending speed at various blending time.

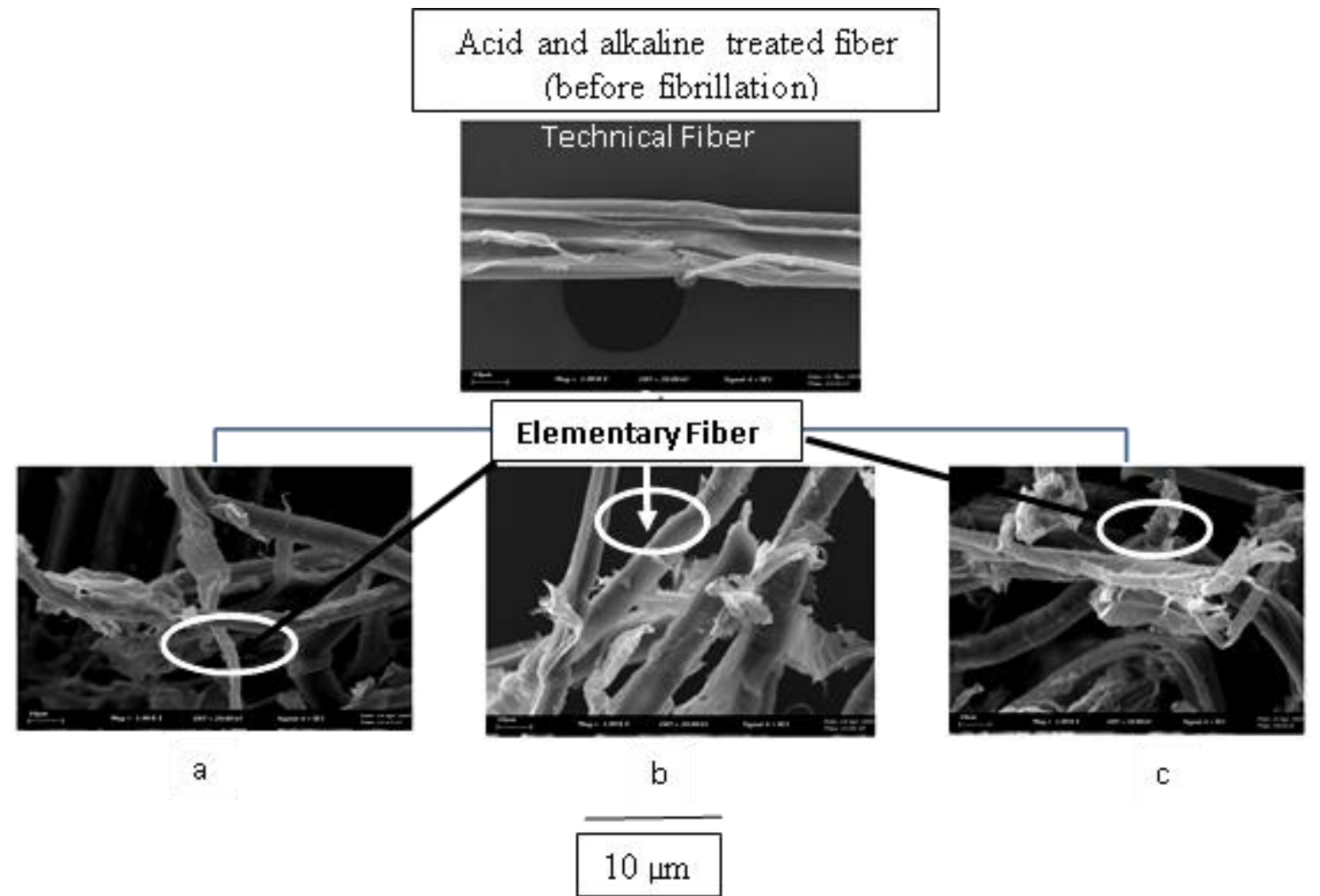

Figure 4. SEM shows the appearance of elementary fiber during fibrillation of kenaf fiber with the surface morphology of Kenaf Fiber with blending time of 15 minutes and blending speed of (a) $7500 \mathrm{rpm}$, (b) $15000 \mathrm{rpm}$ and (c) $23000 \mathrm{rpm}$ obtained from scanning electron microscopy with Magnification of $1000 X$. 
Figure 5 and 6 show the average length and diameter decreased gradually for every blending time and speed respectively. This may be due to the chemical treatment of the kenaf fiber that has weakened the intermolecular bonding between the cellulose. As in Figure 6, it shows that the average diameter at the blending time of 5 minutes was retarded as the speed increased. This could be due to less efficiency of the blending time for the fibrillation process.

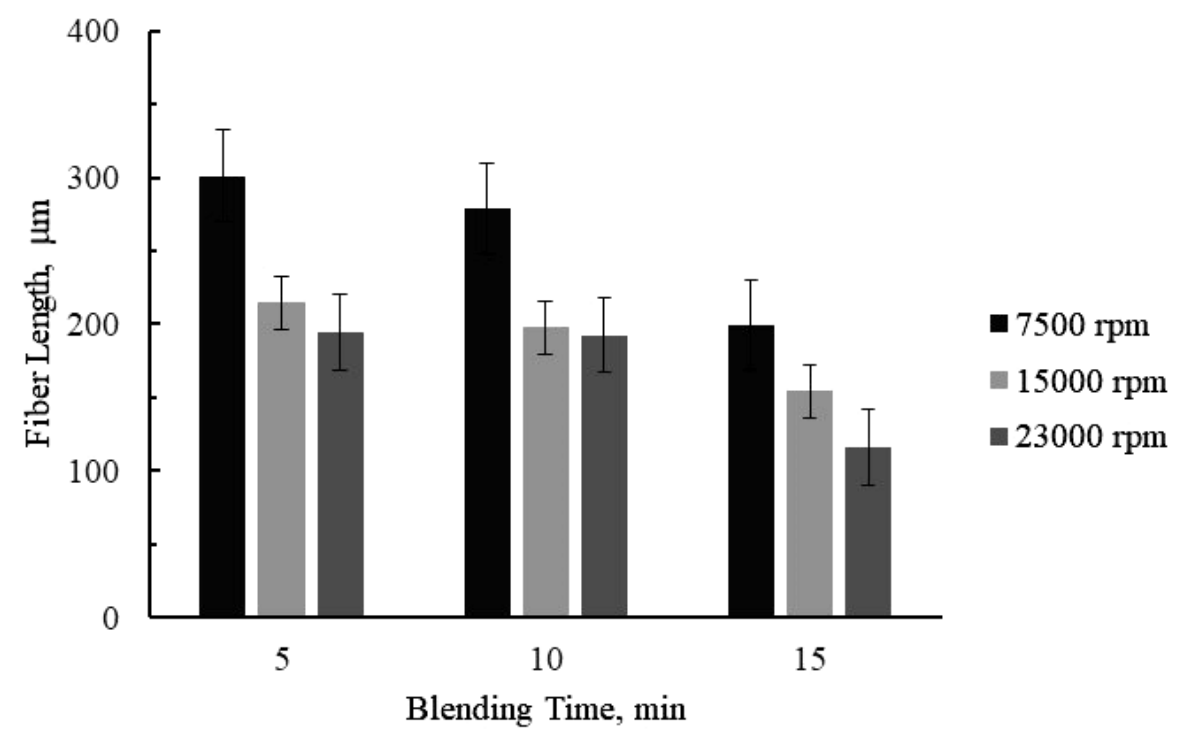

Figure 5. Average length of fibrillated kenaf fiber based on different blending speeds and blending time.

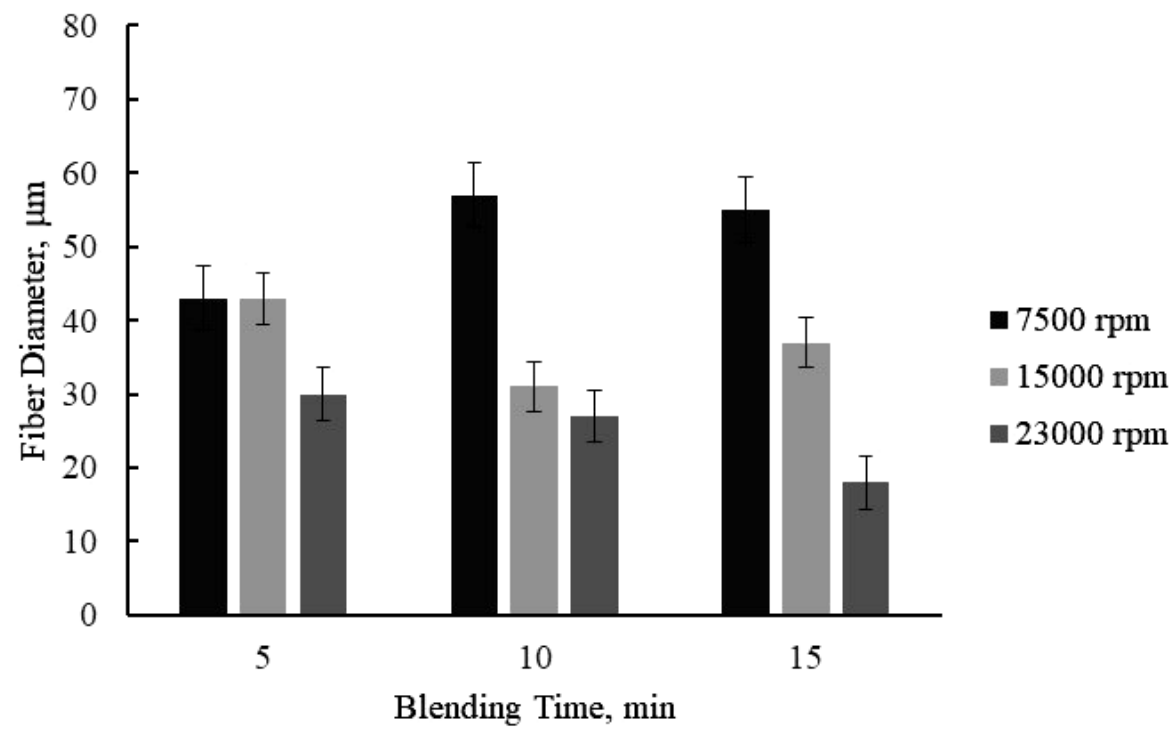

Figure 6. Average diameter of kenaf fiber based on different blending speeds and blending time.

The lengths of the fibers are the shortest at the maximum blending speed and bending time whereas same analysis is observed from the average diameter of the fiber. 


\section{Field Emission Scanning Electron Microscope (FESEM)}

Figure 7, 8 and 9 show the FESEM images of nano fibrillated cellulose at maximum speed of $23000 \mathrm{rpm}$ at various time of 5,10 and 15 minutes. The diameter and portion of the nanofibrils formed increased with increasing blending time. The FESEM images showed that the diameter of the nanofibers was in the range of $10-40 \mathrm{~nm}$.

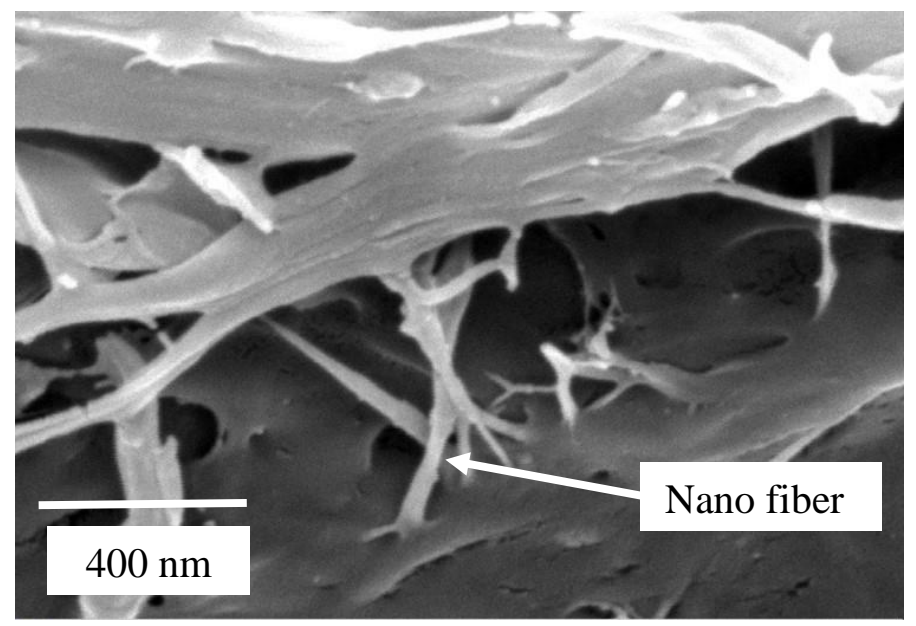

Figure 7. SEM of nano fibrillated cellulose at 23000rpm, 5 minute.

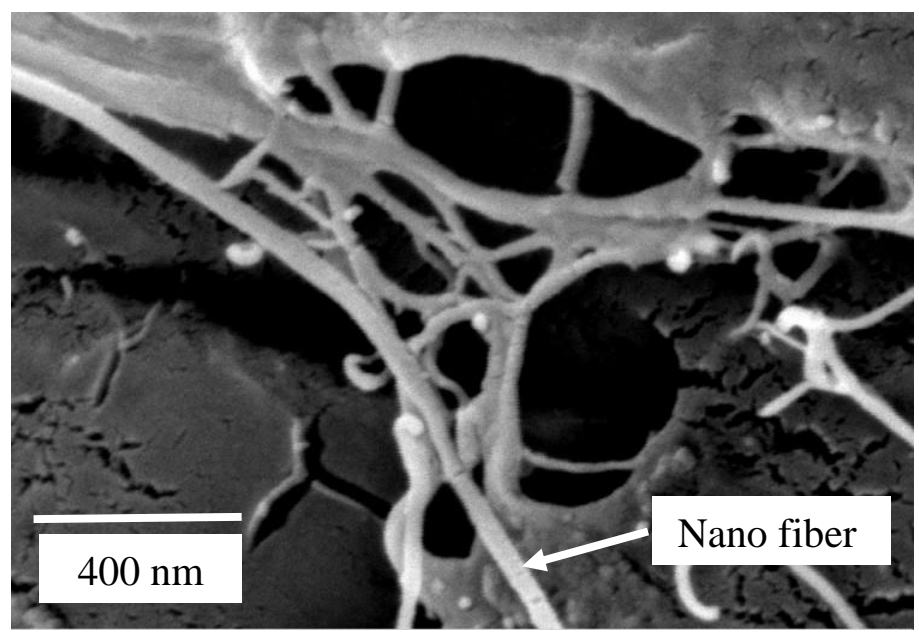

Figure 8. SEM of nano fibrillated cellulose at 23000rpm, 10 minute. 


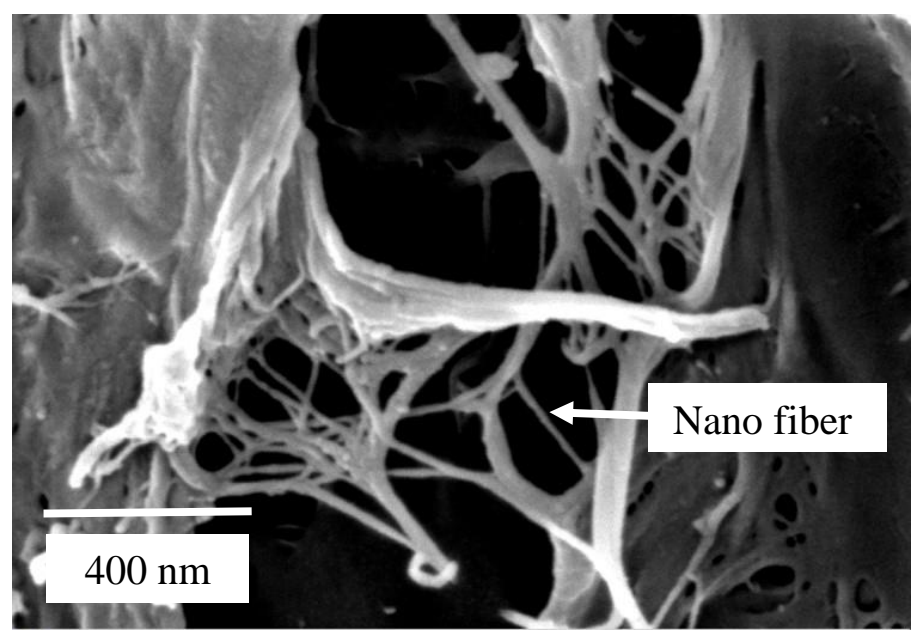

Figure 9. SEM of nano fibrillated cellulose at 23000rpm, 15 minute.

Figure 10 shows the average diameter distribution of nanofibrillated cellolose fibers blending at $23000 \mathrm{rpm}$ with different time. The diameter of NCKF blended at $5 \mathrm{~min}$ was reduced by $58 \%$ from $32.87 \mu \mathrm{m}$ to $13.82 \mu \mathrm{m}$ after treated at $15 \mathrm{~min}$.

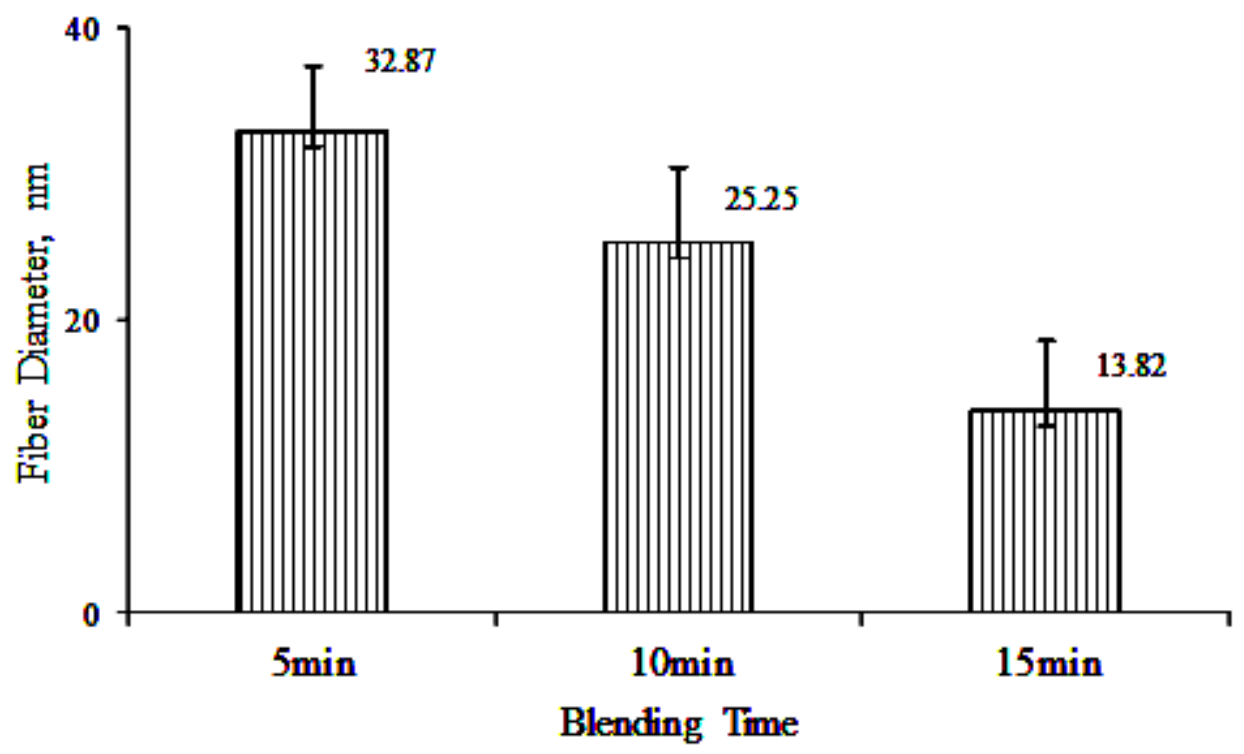

Figure 10. Average diameter of NCKF blended at $23000 \mathrm{rpm}$ with different blending time.

\section{Fourier Transform Infrared Ray (FTIR)}

The FTIR pattern of as received kenaf fiber, chemical treated fiber and fibrillated fiber are shown in Figure 11. The results indicate that a chemical treatment has influences on as received kenaf fiber. Any peak in region $3700-3300 \mathrm{~cm}^{-1}$ confirmed the presence of free O$\mathrm{H}$ stretching, vibration of $\mathrm{OH}$ group in cellulose molecules [25]. A broad band appeared at $3400 \mathrm{~cm}^{-1}$ represents free $\mathrm{OH}$ groups in the cellulose molecules, whereas the bands that appeared between $2800 \mathrm{~cm}^{-1}$ and $2900 \mathrm{~cm}^{-1}$ corresponded to $\mathrm{C}-\mathrm{H}$ absorption bands [26]. As expected, all of the three samples have exhibited peaks in this region; both as received kenaf 
fiber and fibrillated fiber at $3338 \mathrm{~cm}^{-1}$, treated fiber at $3336 \mathrm{~cm}^{-1}$. This hydroxyl activity may be indicating the aromatic and aliphatic of $\mathrm{OH}$ group that is involved in hydrogen bond [27]. The absorption value for the treated kenaf fiber for this stretching vibration was lower than that of the as received fiber means that the crystalline cellulose of kenaf fiber was disrupted during the chemical treatment process at the temperature of $70^{\circ} \mathrm{C}$.

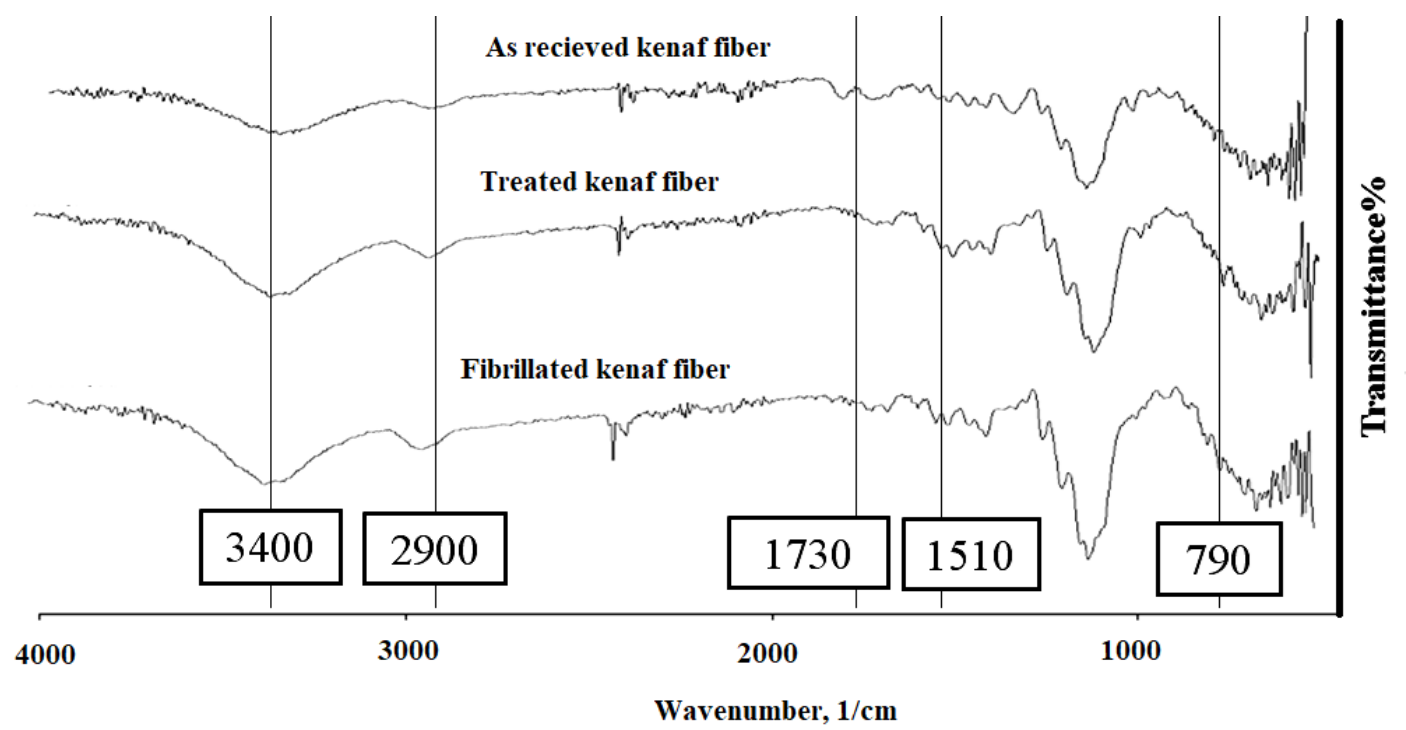

Figure 11. FTIR Spectra of as received kenaf fiber (KF-AR), chemically treated fiber (KF$3 \mathrm{~T})$ and fibrillated fiber at blending speed of 23000rpm at 15 minutes (KF-F23-15).

In addition, the peak appeared at around $2914 \mathrm{~cm}^{-1}$ for the as received kenaf fiber when compared to $2894 \mathrm{~cm}^{-1}$ for the treated and fibrillated fiber indicated that there was C-H stretching occurred. The treated fiber has lower value of these ranges of absorbance which indicates dissolution of the released oligomers, where glucose chain was broken down by the hydrogen bond during the chemical treatment process at high temperature. Figure 11 shows peaks around $1727 \mathrm{~cm}^{-1}$ for the as received kenaf fiber and no peaks for the treated and fibrillated cellulose, respectively. The occurrence of peak could be due to the $\mathrm{C}-\mathrm{O}$ stretching of hemicelluloses and lignin. When there are no peaks present, it indicates that the hemicellulose and lignin was successfully altered during the chemical treatment process.

Peaks from $1510-1650 \mathrm{~cm}^{-1}$ confirmed the presence of $\mathrm{C}=\mathrm{C}$ stretching vibration of aromatic rings from lignin and cellulose. In this region, as received kenaf shows presence of a peak at $1507 \mathrm{~cm}^{-1}$ while treated and fibrillated fiber has shown a peak at $1466 \mathrm{~cm}^{-1}$. This could be similarly due to the removal of lignin content through the treatment process. FTIR peaks from $1246-950 \mathrm{~cm}^{-1}$ are referred to $\mathrm{C}-\mathrm{O}-\mathrm{C}, \mathrm{C}-\mathrm{O}, \mathrm{C}-\mathrm{OH}$ stretching vibration of lignin and polysaccharides from cellulose, lignin and hemicellulose accordingly. The FTIR peak at 793 $\mathrm{cm}^{-1}$ at as received kenaf fiber, $747 \mathrm{~cm}^{-1}$ for treated fiber and $710 \mathrm{~cm}^{-1}$ for fibrillated fiber is attributed to $\mathrm{C}-\mathrm{O}$ bending of aromatic compounds from lignin [28]. Due to the chemical treatments, this rich peak has become weaker in treated fiber and further weakened in fibrillated fiber FTIR plot. The comparison of treated fiber and fibrillated fiber show no significant changes on the functional groups of the kenaf fiber after the fibrillation process. This indicates that the changes of functional group occur during the chemical treatment 
process instead of fibrillation process. Hence, the fibrillation process has no impact on the fibers chemical composition and functional group changes.

\section{Yield of Nano Cellulose fiber}

In order to evaluate the extent of fibrillation, the yield of fibrillation fraction was determined by centrifugation method. This approach was shown to give a good indication about the degree of fibrillation of the nanocellulose fibers. The result of this investigation represents the average value of three replications shown in Table 2. Result shows that the higher blending time had a higher average yield compared to the lower blending time. Removing a large proportion of hemicellulose by chemical pre-treatment will bring the micro fibrils into a closer contact, which favouring their strong interaction through hydrogen bonding. Thus, it renders the fiber harder to fibrillate and required longer time [29].

Table 2. Average yield percentage of NCF with maximum blending speed of $23000 \mathrm{rpm}$ and different blending time.

\begin{tabular}{cccc}
\hline Nomenclature & $\begin{array}{c}\text { Blending Speed } \\
(\mathrm{rpm})\end{array}$ & $\begin{array}{c}\text { Blending Time } \\
(\mathrm{min})\end{array}$ & $\begin{array}{c}\text { Average Yield } \\
5 \%\end{array}$ \\
\hline KF-C-23-5 & & 5 & 10.67 \\
KF-C-23-10 & 23000 & 10 & 15.22 \\
KF-C-23-15 & & 15 & 18.63 \\
\hline
\end{tabular}

\section{Tensile Tests}

The tensile strength and modulus of pure PLA and other NFKC-PLA biocomposites at various blending speed and blending rpm are shown Figure 12, 13 respectively and the addition of anisotropic NFKC to the PLA matrix influences the performance in uniaxial stress. The tensile strength and modulus were improved with increased yield contents nanofiber (Figure 12 and 13).

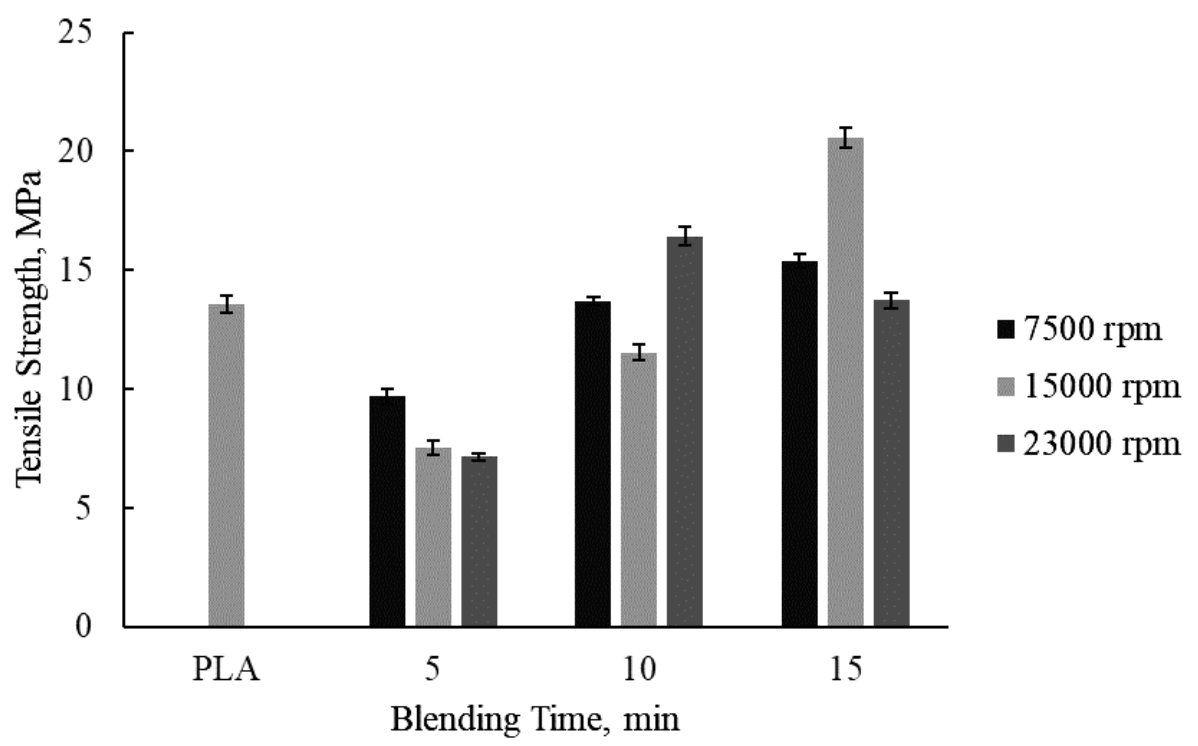

Figure 12. Tensile strength of PLA and NFKC-PLA composites. 
The maximum increase in tensile strength of 59.32\% was observed for NFKC-PLA composite with fibrillation speed and time of $15000 \mathrm{rpm}$ and 15 minutes whereas, the maximum increase in tensile modulus of $143 \%$ was observed for NFKC-PLA composite with fibrillation speed and time of $23000 \mathrm{rpm}$ and 15 minutes as compared to pure PLA. Substantial decrease of the ultimate tensile strength (UTS) for composites with five minutes blending at all three blending speeds from the $13.13 \mathrm{MPa}$ that has the PLA without any filler may infer the non-homogeneous distribution of fibers in the samples. The positive impact of the nanofibers especially in the composite strength indicated that the used nanofibers have good mechanical properties and that is interaction between the NFKC and PLA. However, when the NFKC content obtained from $23000 \mathrm{rpm}$ with higher blending time, tensile parameters decreased because NFKC dispersed unevenly, increased mechanical damage to the crystalline cellulose and agglomerate, leading to stress concentration and deterioration of tensile stress transfer between matrix and filler even though average yield is higher [30, 31]. In general, the behavior of composites under uniaxial stress is similar to the obtained in previous publications, with an increase in the UTS and a decrease in the strain at fracture when mechanically modified cellulosic fillers are added [32].

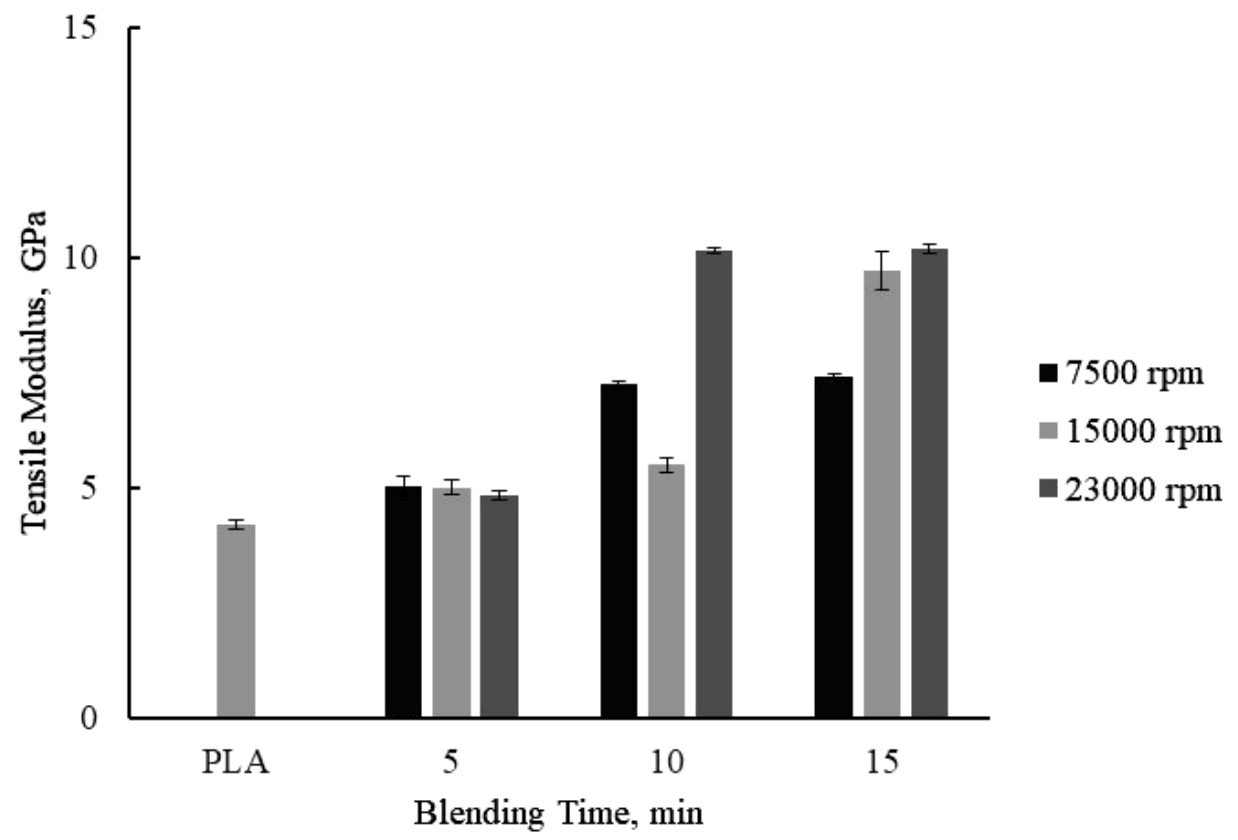

Figure 13. Tensile modulus of PLA and NFKC-PLA composites.

\section{Composite Morphology Analysis}

Figure 14 shows SEM tensile fracture surfaces of pure PLA and NFKC-PLA composites with NFKC obtained at blending speed of $7500 \mathrm{rpm}, 15000 \mathrm{rpm}$ and $23000 \mathrm{rpm}$ for blending time of 15 minutes. Pure PLA shows the typical streamline or riverlike pattern with cleavage facets that are attribute of brittle fracture (Figure 15a). Chemical treatment with macro and micro fibrillation of kenaf fibers clearly show the rough surface of the fiber along with fiber pull out. The rougher surface of fibers expanded the area of interaction with PLA, and had better interface properties than smooth-surfaced PLA [33,34]. It can also be attributed that the 
surface of NFKC was rough and uneven [cf. to Figure 7,8,9], and these features facilitated the formation of three-dimensional multi-scale interface interaction with PLA, thus greatly improving the mechanical properties.

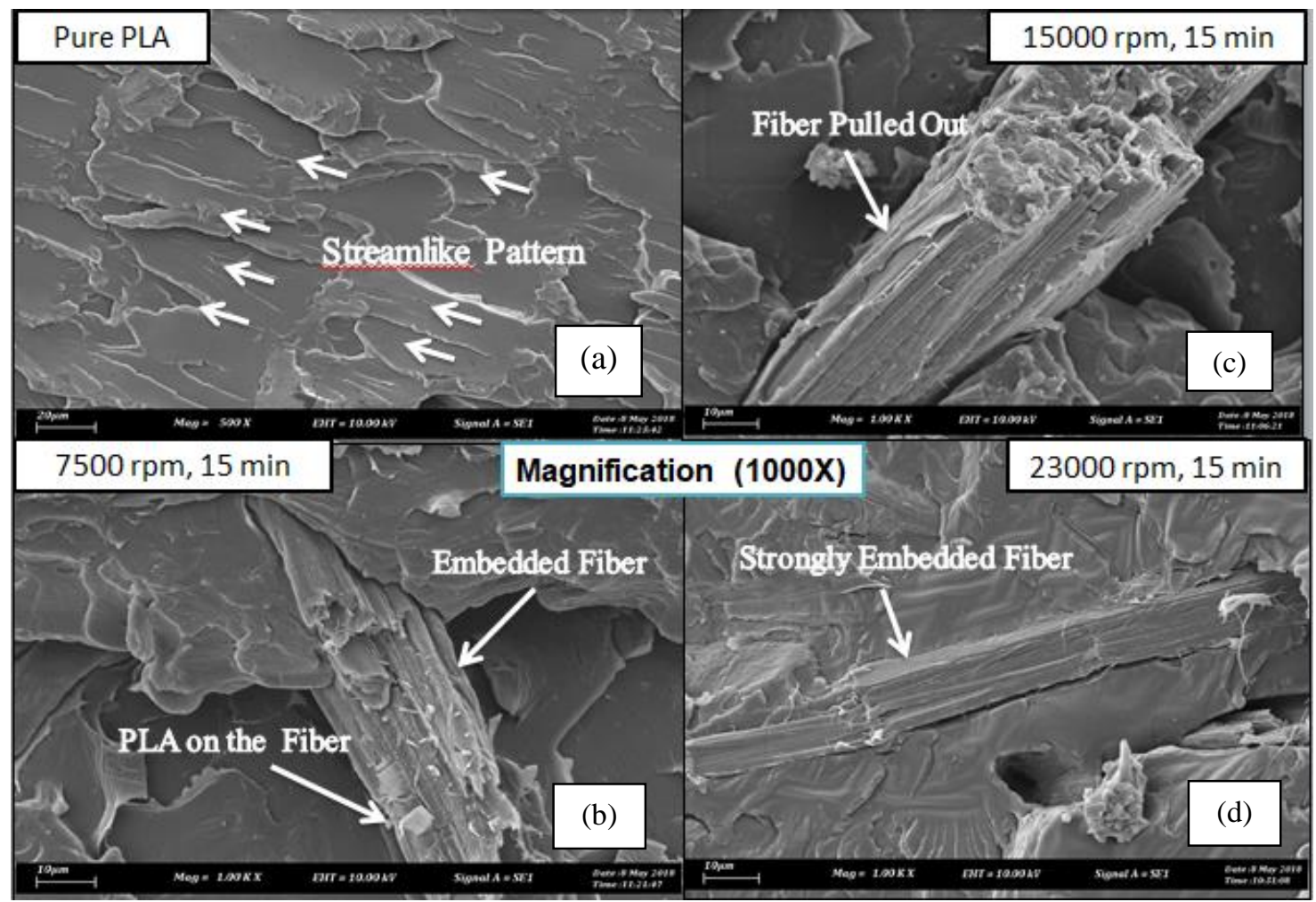

Figure 14. SEM tensile fracture surface of (a) pure PLA and reinforced PLA composites with NFKC at (b) $7500 \mathrm{rpm}$, (c) $15000 \mathrm{rpm}$ and (d) $23000 \mathrm{rpm}$ for 15 minutes.

\section{CONCLUSION}

NFKC derived from kenaf fiber after varying chemico-mechanical treatments were reinforced into poly lactic acid (PLA) and were successfully fabricated by moldcompression. Successive acid and alkali treatments followed by blending at high blending speeds and time clearly showed the removal of impurities as well as successive reduction in diameters of fibers from macro to micro and micro to nano dimension level respectively. The FTIR patterns of as received kenaf fiber, chemical treated fiber and fibrillated fiber showed that there is presence of $\mathrm{OH}$ group, disruption of crystallinity of cellulose, alteration of hemicellulose and lignin and removal of lignin. The average length and diameter of fibrillated fibers decreased as the as the blending speed and time increase. The evaluation of the mechanical properties of the PLA and its nanocomposite showed a trend that the tensile strength and modulus were improved with increased blending speed and time. The modulus of the PLA was increased from 4.2 GPa to $10.21 \mathrm{GPa}$ with the addition of $5 \mathrm{wt} . \%$ fibrillated kenaf fibers, and a $60 \%$ increase of tensile strength was observed. The biocomposites presented a high strength realizes the synergistic effects of reinforcement and PLA in composites. 


\section{ACKNOWLEDGEMENT}

The authors would like to thank to the Universiti Teknikal Malaysia Melaka for providing laboratory facilities and financial assistance.

\section{REFERENCES}

[1] Li C, Guo J, Jiang T, Zhang X, Xia L, Wu H, Guo S, Zhang X. Extensional flowinduced hybrid crystalline fibrils (shish) in CNT/PLA 349 nanocomposite. Carbon 2018;129:720-726.

[2] Sookprasert P, Hinchiranan N. Morphology, mechanical and thermal properties of poly (lactic acid) (PLA)/natural rubber (NR) blends compatibilized by NR-graftPLA. Journal of Materials Research 2017; 32:788-796.

[3] Jamshidian M, Tehrany E A, Imran M, Jacquot M, Desobry S. Poly-Lactic Acid: Production, applications, nanocomposites, and release studies. Comprehensive Reviews in Food Science and Food Safety 2010; 9(5):552-571.

[4] Yao Q, Cosme J G L, Xu T, Miszuk J M, Picciani P H S, Fong H, Sun H. Three dimensional electrospun PCL/PLA blend nanofibrous scaffolds with significantly improved stem cells osteogenic differentiation and cranial bone formation. Biomaterials 2017; 15:115-123.

[5] Hu C, Li Z, Wang Y, Gao J, Dai K, Zheng G, Liu C, Shen C, Song H, Guo Z. Comparative assessment of the strain-sensing behaviors of polylactic acid 358 nanocomposites: reduced graphene oxide or carbon nanotubes. Journal of Materials Chemistry C. 2017; 9:2318-2325.

[6] Nagarajan V, Mohanty A K, Misratt M. Perspective on polylactic acid (PLA) based sustainable materials for durable applications: focus on toughness and heat resistance. ACS Sustainable Chemistry \& Engineering. 2016; 5:A-R.

[7] Li C, Wang F, Chen P, Zhang Z, Guidoin R, Wang L. Preventing collapsing of vascular scaffolds: The mechanical behavior of PLA/PCL composite structure prostheses during in vitro degradation. Journal of the Mechanical Behavior of Biomedical Materials. 2017; 8:455-462.

[8] Alkbir M F M, Sapuan, S M, Nuraini A A, Ishak M R. Fibre properties and crashworthiness parameters of natural fibre-reinforced composite structure: A literature review. Composite Structures 2016; 148:59-73.

[9] Tahir P M, Amel B A, Syeed O A, Saiful A, Zakiah A. Retting process of some bast plant fibres and its effect on fibre quality: A Review. BioResources 2011; 10(4):1-8.

[10] Jonoobi M, Harun J, Mathew A P, Oksman, K. Mechanical properties of cellulose nanofiber (CNF) reinforced polylactic acid (PLA) prepared by twin screw extrusion. Composites Science and Technology 2010; 70(12):1742-1747.

[11] Larsson K, Berglund L A, Ankerfors M T L. Polylactide latex/nanofibrillated cellulose bionanocomposites of high nanofibrillated cellulose content and nanopaper network structure prepared by a papermaking route. Polymers and Polymer Composites 2013; 21(7):449-456.

[12] Siro I, Plackett D. Microfibrillated cellulose and new nanocomposite materials:a review. Cellulose. 2010, 17:459-494. 
[13] Andresen M, Stenstad P, Moretro T, Langsrud S, Syverud K, Johansson LS, Stenius P. Nonleaching antimicrobial films prepared from surface-modified microfibrillated cellulose. Biomacromolecules 2007; 8:2149-2156.

[14] Habibi Y, Mahrouz M, Vignon M R. Microfibrillated cellulose from the peel of prickly pear fruits. Food Chemistry 2009; 115:423-429.

[15] Chen C, Li D, Hu Q, Wang R. Properties of polymethyl methacrylate-based nanocomposites: Reinforced with ultra-long chitin nanofiber extracted from crab shells. Materials \& Design 2014; 56:1049-1056.

[16] Velásquez-Cock J, Castro C, Gañán P, Osorio M, Zuluaga R. Influence of the maturation time on the physico-chemical properties of nanocellulose and associated constituents isolated from pseudostems of banana plant. Industrial Crops and Products 2016; 83:551-560

[17] Oksman K, Mathew A P, Bondeson D, Kvien I. Manufacturing process of cellulose whiskers/polylactic acid nanocomposites. Composites Science and Technology 2006; 66:2766-2784.

[18] Mathew A P, Chakraborthy A, Oksman K, Sain M. The structure and mechanical properties of cellulose nanocomposites prepared by twin screw extrusion. In Oksman K, Sain M, editors. Cellulose nanocomposites: processing, characterization and properties. USA: Oxford University Press. ACS Symposium Series. 2006; 938-945.

[19] Bondeson, Daniel, Oksman Kristiina. Dispersion and characteristics of surfactant modified cellulose whiskers nanocomposites. Composite Interfaces 2007; 14:617630.

[20] Bondeson, Daniel, Oksman, Kristiina. Polylactic acid/cellulose whisker nanocomposites modified by polyvinyl alcohol. Composites Part A 2007; 38:24862492.

[21] Okubo K, Fujii T, Thostenson E T. Multi-scale hybrid biocomposite: processing and mechanical characterization of bamboo fiber reinforced PLA with microfibrillated cellulose. Composites Part A 2009; 40:469-475.

[22] Le Moigne N, Bikard J, Navard P. Rotation and contraction of native and regenerated cellulose fibers upon swelling and dissolution: the role of morphological and stress unbalances. Cellulose 2010; 17:507-519.

[23] Turbak A F, Snyder F W, Sandberg K R, Microfibrilated cellulose, a new cellulose product: properties, uses, and commercial potential. Journal of Applied Polymer Science, Applied Polymer Symposium 1983; 37:815-827.

[24] Herrick F W, Casebier R L, Hamilton J K, Sandberg K R. Microfibrillated cellulose: morphology and accessibility. Journal of Applied Polymer Science:Applied Polymer Symposium 1983; 37:797-813.

[25] Ketabchi, M R, Khalid M, Ratnam C T, Walvekar R, Abdullah L C, Ketabchi M R, Abdullah L C. Sonosynthesis of microcellulose from kenaf fiber: Optimization of process parameters. Journal of Natural Fibers 2017; 0(0):1-13.

[26] Akhtar M N, Sulong A B, Radzi M K F, Ismail N F, Raza, M R, Muhamad N, Khan M A. Influence of alkaline treatment and fiber loading on the physical and mechanical properties of kenaf/polypropylene composites for variety of applications. Progress in Natural Science: Materials International 2016; 26(6):657-664.

[27] Hashim S N A S, Zakaria S, Jaafar S N S, Hua C C. Purification of empty fruit bunch (EFB) and kenaf soda lignin with acidified water 2014; 129:129-135. 
[28] Parshetti G K, Hoekman K S, Balasubramanian R. Chemical, structural and combustion characteristics of carbonaceous products obtained by hydrothermal carbonization of palm empty fruit bunches. Bioresource Technology 2013; 135:683689.

[29] Chaker A, Alila S, Mutje P, Vilar M R, Boufi S. Key role of the hemicellulose content and the cell morphology on the nanofibralltion effectiveness of cellulose pulps. Cellulose 2013; 20(6):2863-2875.

[30] Fu S Y, Feng X Q, Lauke B, Mai Y W. Effects of particle size, particle/matrix interface adhesion and particle loading on mechanical properties of particulatepolymer composites. Composites Part B: Engineering 2008; 39:933-939.

[31] Awadhiya A, Kumar D, Rathore K, Fatma B, Verma V. Synthesis and characterization of agarose-bacterial cellulose biodegradable composites. Polymer Bulletin 2017; 74(7):2887-2903.

[32] Robles E, Urruzola I, Labidi J, Serrano L. Surface-modified nano-cellulose as reinforcement in poly(lactic acid) to conform new composites. Industrial Crops and Products 2015; 71:44-53.

[33] Geng L H, Peng X F, Jing X, Li L W, Huang A, Xu B P, Chen B Y, Mi H Y. Investigation of poly (L-lactic acid)/graphene oxide composites crystallization and nanopore foaming behaviors via supercritical carbon dioxide low temperature foaming. Journal of Materials Research 2016; 31:348-345.

[34] Li Y, Chen C, Li J, Sun X S. Photoactivity of Poly (lactic acid) nanocomposites modulated by $\mathrm{TiO}_{2}$ nanofillers. Journal of Applied Polymer Science 2014; 131:40241. 